\title{
O Manhês e o Desenvolvimento da Comunicação Adulto-Bebê: Uma Revisão da Literatura com uma Proposta de Análise Microgenética das Trocas Mãe-Bebê
}

\author{
Letícia Scorsi* \& Maria da Conceição Diniz Pereira de Lyra ${ }^{* *}$ \\ Universidade Federal de Pernambuco, Recife, Brasil
}

\begin{abstract}
RESUMO
Apresentamos uma revisão da literatura sobre o manhês - fala diferenciada dirigida a bebês ressaltando argumentos para uma proposta de análise microgenética das trocas mãe-bebê. Destacamos aspectos da teoria dos Sistemas Dinâmicos, que combina análises micro e macrogenética para mapear o processo de desenvolvimento de um fenômeno, e características do manhês que permitem supor seu papel integrado no desenvolvimento da comunicação mãe-bebê. Discutimos a concepção de universalidade versus a de generalidade e identificamos padrões de organização da comunicação e sua variabilidade resultantes do ajuste entre parceiros específicos. Concebemos as trocas adulto-bebê como co-reguladas, exibindo transformações ao longo da sua história de co-construção. Ilustramos nossa proposta para o estudo do manhês com exemplos de uma análise microgenética da fala da mãe.

Palavras-chave: manhês; generalidade; co-regulação; microgênese.
\end{abstract}

\begin{abstract}
Motherese and the Development of Adult-Infant Communication: A Literature Review With a Proposal For a Microgenetic Analysis Of Mother-Infant Exchanges

A literature review about motherese - a differentiated speech directed to infants - is presented to support a proposal for a microgenetic analysis of mother-infant exchanges. We present the theory of Dynamic Systems, which combines micro and macrogenetic analysis for mapping the process of change of the given phenomenon, and characteristics of motherese that allows us to assume that it integrates the development of mother-infant communication. Instead of dealing with it as a universal phenomenon, we focus on its generality, organizational patterns and variability that result from the adjustment between specific partners. The adult-baby exchanges are taken as co-regulated, exhibiting transformations through its co-constructed history. Our proposal to study motherese is illustrated through examples of a microgenetic analysis of mother's speech.
\end{abstract}

Keywords: motherese; generality; co-regulation; microgenesis.

A maneira como os adultos agem com bebês é diferente de como agem com crianças mais velhas e outros adultos. A fala dirigida ao bebê, chamada de "manhês" (motherese, baby-talk, child-directed speech, infant-directed speech), pode ser considerada como o mais claro exemplo desta diferença (Ferguson, 1964, Schieffelin, 1979, Snow, 1977, Stern, 1977, Stern, Spieker \& MacKain, 1982).

Neste artigo, revisamos a literatura sobre o $m a$ nhês, tendo como principal objetivo destacar a importância de estudá-lo como uma co-construção entre a mãe e seu bebê que ocorre inserida no sistema comunicativo, e incluímos, a título de ilustração, uma análise microgenética da comunicação mãe-bebê. Considerando a referida revisão, identificamos as características que permitem supor que esta fala integra o desenvolvimento da comunicação adulto-bebê compreendido como um sistema em desenvolvimento. Chamamos, sobretudo, a atenção para a necessidade de estudá-la de uma perspectiva microgenética visando compreendê-la como emergindo e se transformando nesse sistema de comunicação ao longo do tempo. Discuti-

\footnotetext{
* Endereço para correspondência: Letícia Scorsi - leticiascorsi@ gmail.com

** Endereço para correspondência: Maria da Conceição Diniz Pereira Lyra - marialyra2007@ gmail.com
} 
mos a universalidade, a variabilidade e as características desenvolvimentistas do manhês apontadas na literatura na área. Sugerimos que uma análise microgenética do desenvolvimento do manhês permite entendêlo no seu processo de transformação contribuindo, desta forma, para integrar tanto a variabilidade apontada na literatura como as características de universalidade - melhor compreendida como generalidade do manhês. Além disso, desvios no desenvolvimento do manhês, como aqueles encontrados nas mães portadoras de depressão (Herrera, Reissland \& Shepherd, 2004; Murray, 1998), por exemplo, podem ser explorados na mutualidade co-construída entre essas mães e seus bebês, permitindo identificar os mecanismos através dos quais tanto o bebê como sua mãe contribuem para o desenrolar do desenvolvimento atípico.

Uma perspectiva sistêmica e dinâmica nos oferece a identificação de padrões dinâmicos de organização. Esses padrões apresentam particularidades porque dependem da diversidade das situações e das características culturais e individuais uma vez que resultam do ajuste mútuo entre parceiros específicos. Propomos que o manhês participa do desenvolvimento do bebê como resultado de um processo característico à dinâmica das relações entre os parceiros mãe e bebê.

\section{MÉTODO}

Este trabalho, ao consistir em uma revisão bibliográfica, seguida de uma proposta de análise microgenética da comunicação mãe-bebê, procura, sobretudo, identificar aqueles estudos nos quais se destacam aspectos passíveis de sugerir como a fala da mãe, concebida como manhês, está sendo investigada do ponto de vista da relação mãe-bebê. Busca-se, assim, um conhecimento e aprofundamento sobre o "estado da arte" sobre o manhês naquilo que se pode situar e avaliar sua compreensão a partir de uma investigação microgenética do processo de comunicação mãe-bebê. Desta forma, ancoramos esta revisão bibliográfica em uma busca empírica e teórica que visa dar fundamentos para a nossa proposta de análise microgenética do processo de transformação e construção das trocas mãe-bebê, também incluída neste artigo.

Para a execução da revisão da bibliografia foram utilizados textos selecionados em livros considerados clássicos na área da Psicologia do Desenvolvimento, comunicação mãe-bebê. Além disto, foram utilizadas as seguintes bases de dados: portal Scielo - Scientific Electronic Library Online, Lilacs, ISI Web of Knowledge e Google Acadêmico. Utilizamos como pala- vras-chave em português os termos: manhês, fala da mãe, fala maternal ou materna, discurso materno, fala dirigida a crianças. Em inglês as palavras-chave foram: motherese, baby-talk, mother's speech, infantdirected speech, child-directed speech, maternal speech, prosody. Desta busca resultaram diversos abstracts de artigos científicos publicados entre os anos 1950 e 2007. De posse desses abstracts, sendo 97 no total, analisamos quais dos textos apresentavam aderência aos eixos norteadores de nosso trabalho (os mesmo estão especificados ao longo deste artigo, como, por exemplo, a perspectiva sistêmica e dinâmica, a análise microgenética, entre outros). Desta análise resultaram 40 artigos que serviram de base para nossas colocações.

\section{A PERSPECTIVA SISTÊMICA E DINÂMICA}

Adotar uma perspectiva dinâmica para compreender fenômenos psicológicos implica trabalhar com a ideia de mundo, e indivíduos, em constante transformação (Lyra, 2000, 2007). Neste referencial a dinâmica não é considerada uma imperfeição, mas sim a base para a investigação destes fenômenos (Marková, 2006). Isto quer dizer que o fenômeno é estudado exatamente a partir do processo de mudança que nele ocorre (Lyra, 2000, 2007).

Van Geert (2003) esclarece que um sistema dinâmico é um conjunto de fenômenos, componentes, ou variáveis que apresentam relação entre si, afetando uns aos outros de modo a se modificarem ao longo do tempo. Nesta perspectiva o desenvolvimento não é concebido como algo que tem um planejamento prédefinido, mas como resultado de mecanismos de autoorganização das relações que estão implicadas nos sistemas. Assim, pesquisas sob a perspectiva dos Sistemas Dinâmicos buscam o processo de transformação que guia o desenvolvimento através dos padrões de organização da ação conjunta dos elementos que compõem o sistema. E, através da combinação da micro-análise (tempo real) e da macro-análise (tempo do desenvolvimento), pode-se mapear o processo de mudança de um determinado fenômeno.

Por "tempo real" compreende-se o acompanhamento contínuo, ou quase-contínuo do fenômeno a ser estudado, de modo que a análise pode ser conduzida segundo-a-segundo, minuto-a-minuto, dia-a-dia, etc., dependendo da possibilidade de se identificar as transformações nas relações que permitam reconhecer diferentes padrões de organização (Granott \& Parziale, 2002). Esta análise, chamada de "análise microgenéti- 
ca" tem por objetivo capturar a dinâmica histórica que caracteriza o desenvolvimento (Granott \& Parziale, 2002; Lee \& Karmiloff-Smith, 2002; Thelen \& Corbetta, 2002).

Em seguida, com base nos dados obtidos através da análise microgenética, identificam-se os agrupamentos possíveis que exibem padrões segundo os quais aquele fenômeno se organiza ao longo de um período do desenvolvimento. Isto é chamado de "tempo de desenvolvimento". Estes períodos podem ser também chamados de estágios ou etapas do desenvolvimento. A "análise macrogenética" investiga as características desses períodos (Lyra, 2006).

\section{UNIVERSALIDADE VERSUS GENERALIDADE}

Comecemos por considerar a universalidade do manhês. Propor que um fenômeno é universal significa compreender que suas características são comuns a todos os componentes de uma dada espécie. Podemos conceber duas formas de universalidade: uma genética, que se liga uma idéia de pré-determinação; e outra teleológica, que é encarada em função de uma causa final, onde se atribui ao resultado uma influência sobre o processo que o conduz. Porém, de acordo com a perspectiva por nós adotada, ao invés de se trabalhar sobre a universalidade de um dado fenômeno a partir de princípios decorrentes da dotação genética ou teleológicos, cabe buscar a generalidade do mesmo a partir da identificação dos padrões de organização que assumem as variáveis envolvidas no sistema em estudo. Esta noção nos parece mais apropriada, pois abarca a variabilidade, ou seja, as particularidades decorrentes dos limites culturais e individuais, do ajuste entre os parceiros e da diversidade de situações com as quais eles se deparem.

No caso do manhês, entender este fenômeno como universal significa pressupor que adultos pertencentes a qualquer grupo social modificam similarmente sua fala quando interagem com bebês. $\mathrm{O}$ estudo realizado por Ferguson (1964) parece sustentar tal afirmação, pois o autor encontrou similaridade entre o uso do manhês em seis diferentes línguas de culturas diversas: o uso de mais substantivos do que pronomes; muitas das frases construídas na terceira pessoa do singular, ao invés da primeira ou segunda pessoa (e.g. "A mamãe vai pegar o nenê"); nomes no diminutivo; apelidos; enunciados sobre partes e funções do corpo, animais e jogos.

Estudos sob a perspectiva da seleção natural também parecem indicar esta mesma direção ao sugerir que as vocalizações diferenciadas das mães são resultado de um processo evolutivo. Segundo Sheridan (2005), o fato dos seres humanos terem se tornado bípedes selecionou indivíduos com pelve menores, que selecionou recém-nascidos imaturos que, por sua vez, pressionou as vocalizações das mães para sons tranqüilizadores, tal como ocorrem no manhês. Assim, com a evolução dos hominídeos, a comunicação entre mãe e bebê passou a ser distal e a fala da mãe serve de substituta ao contato físico e os sons de conforto e de leve repreensão emitidos pela mãe servem ao propósito de fortalecer a relação com o bebê (Falk, 2004).

Portanto, de acordo com essa perspectiva, pode-se argumentar que o uso desta fala diferenciada se torna uma característica comum a toda a espécie humana. Por exemplo, segundo Matychuck (2005), esta fala estaria presente mesmo em culturas nas quais seus componentes não acreditam utilizar-se da mesma, sendo empregada de maneiras diversas, incluindo outras pessoas que não sejam pais do bebê. Observamos ainda que, embora Fogel seja um dos mais ferrenhos proponentes da idéia de co-construção da relação entre a mãe e o bebê, (Fogel, 1992; 1993; Fogel \& Thelen, 1987) ele também coloca argumentos que favorecem a noção de que esta fala se constitui em um fenômeno universal. Todavia, segundo o autor (Fogel, 1997), este fato se deve à semelhança do sistema mãebebê. Isto é, uma vez que bebês são similares em todo o mundo, eles devem evocar comportamentos análogos nos adultos à sua volta. A universalidade assim concebida é sistêmica e comporta a variabilidade. Ele aponta ainda que todas as mães usam o manhês quando se comunicam com seus bebês, mas mães ocidentais depositam maior crédito no discurso, sendo esta a modalidade principal de estimulação de bebês recémnascidos. Mães de outras culturas, por sua vez, fazem uso de outras formas não vocais de estímulo. Ao afirmar que algumas qualidades do manhês aparecem inclusive em mães que utilizam a língua de sinais para se comunicarem com seus filhos (ritmo mais lento, repetições, e movimentos exagerados relacionados a cada sinal), Fogel (1997) sugere a similitude do sistema mãe-bebê mesmo em condições de déficit sensorial do bebê.

Entretanto, o estudo realizado por Schieffelin (1979) parece se contrapor à universalidade do $m a$ nhês. Segundo a autora, os integrantes de um grupo de Kalulis na Papua-Nova Guiné não fazem uso do léxico do manhês com crianças e também não acham boa tática utilizar formas infantilizadas para ensinar as crianças a falar por tratar-se de uma maneira mais 
difícil de linguagem. Ela aponta que quando as mães Kaluli estão interagindo com seus bebês há um modo específico de interação, mas esta interação não inclui o uso do manhês.

O fato de existirem contradições sobre a universalidade do manhês reforça a nossa proposta acerca da necessidade de estudá-lo longitudinalmente, investigando como ele é co-construído no sistema de comunicação ao longo do tempo. Deste sistema participam a mãe, com suas concepções e valores, e o bebê com seus limites e possibilidades, sejam eles considerados normais ou portadores de distúrbios e/ou patologias. Padrões de organização da relação mãe-bebê que se sucedem no tempo e que resultam do ajuste mútuo entre parceiros específicos podem integrar tanto o que existe de generalizável como a variabilidade que decorre da diversidade de situações e de características culturais e individuais. Desta forma, os processos de construção e os sucessivos padrões de organização que descrevem o desenvolvimento da comunicação no início da vida pós-natal vão integrar o manhês e seu papel construtivo nesta comunicação.

\section{QUALIDADES GERAIS DO MANHÊS}

Ainda que a discussão a respeito da universalidade do manhês deva ser mantida, devemos observar as qualidades gerais desta fala. Algumas delas são assinaladas em comparação à fala dirigida a adultos (adult-directed speech - AD) e explicitam-se principalmente suas diferenças. Trainor, Austin e Desjardins (2000) indicam que tais diferenças se devem, pelo menos em parte, ao fato de a $A D$ típica exibir uma expressão emocional mais contida do que o manhês típico. Contudo, mesmo que existam semelhanças entre estes dois tipos de fala, é fato que o manhês se diferencia. Seus atributos mais evidentes se referem às suas características prosódicas exageradas em relação à fala dirigida a adultos e a alguns aspectos do seu conteúdo.

\section{Características Prosódicas e Conteúdo}

O termo "prosódia"1, neste caso, refere-se à pronúncia das palavras, entonação e ênfase nas sílabas tônicas. Em relação à $A D$, no manhês a entonação é exagerada e o som é mais alto ${ }^{2}$ (Cooper, Abraham, Berman \& Staska, 1997; Stern, 1977). Trata-se de uma fala mais cadenciada e que, portanto, exibe um ritmo diferenciado. Além disto, as pausas entre os enunciados são mais longas (Snow, 1977; Stern, 1977).
As mudanças na agudeza do som e no volume são mais lentas, conferindo-lhe um tom mais dramático do que a $A D$ (Stern, 1977). Este exagero prosódico traz uma qualidade de cantiga ao manhês, assemelhando-o a uma melodia (Trainor et al., 2000) e resultando numa extensão do som mais larga. $\mathrm{O}$ manhês falado por mães norte-americanas, russas, suecas, chinesas e norueguesas apresentou vogais mais extremas, com o espaço entre elas acusticamente esticado e o triângulo das vogais /i/, /a/ e /u/ maior do que na fala dirigida a adultos (Englund \& Behne, 2005; Kuhl et al., 1997; Liu, Kuhl \& Tsao, 2003).

Em suma, as características principais do manhês são: exagero, diminuição na velocidade, no ritmo e na melodia (Fogel, 1997). Por conta dessas variações o que sobressai quando se vê uma mãe conversando com seu bebê recém-nascido é como ela fala com ele, mais do que o que ela fala (Stern, 1977).

Com relação ao conteúdo desta fala, seus enunciados apresentam frases sintática e semanticamente mais simples do que a $A D$ (Cavalcante, 2005; Cooper et al., 1997; Messer, 1994; Snow, 1977; Stern, 1977). As sentenças são mais curtas e centradas na experiência do bebê, onde há um grande número de perguntas e imperativos. Nos primeiros meses há poucas frases diretivas, de controle ou correções (Snow, 1977). Os enunciados apresentam principalmente frases no presente - sobre o "aqui e agora" - com mais substantivos concretos do que abstratos. Observa-se ainda poucos modificadores (adjetivos e advérbios), pequenas variações de vocabulário, uma tendência para mais nomes próprios do que pronomes (Messer, 1994), além de itens lexicais infantilizados - palavras modificadas ou no diminutivo (Ferguson, 1964; Cavalcante, 2005). Pode haver também uma predominância do uso de palavras mais curtas, i.e. mais palavras monossilábicas do que polissilábicas (Redford, Davis \& Miikkulainen, 2004).

\section{Especificidades no Manhês}

A despeito destes padrões gerais do manhês, diversas especificidades propiciam variações no uso desta fala. Por exemplo, mães japonesas em comparação a mães norte-americanas usam mais vocalizações negativas, como proibições e expressões de sentimentos negativos, e quando estão engajadas numa interação divertida com os bebês elas usam mais sons sem sentido e mais manhês (Fogel, 1997). Das mães observadas por Henning, Striano e Lieven (2005), aquelas com níveis educacionais mais altos apresentaram vo- 
cabulários mais ricos, enunciados mais longos e poucos enunciados contendo apenas uma palavra. Além disto, pais usam o manhês de forma diversa das mães, produzindo enunciados mais detalhados, nomeando objetos e também pequenos detalhes dos mesmos (e.g. cor, textura, familiaridade com o objeto, etc.). Eles parecem transformar o objeto em algo mais real ao fazer, por exemplo, uma vaca de brinquedo mugir (Fogel, 1997). Os pais também se configuram parceiros mais desafiadores para as crianças, pois produzem mais questões abertas (e.g., "Por que...?", "Quando...?") e requerem mais esclarecimentos do que as mães (Rowe, Coker \& Pan, 2004). Temos ainda que mães de meninos observadas por Braz e Salomão (2002), emitiram-lhe mais diretivos (comandos com o intuito de dirigir o comportamento, ou verbalização da criança), enquanto que mães de meninas emitiram-lhe mais solicitações (perguntas ou pedidos à criança, solicitando-lhe uma resposta verbal ou não verbal). Especificamente com relação aos diretivos, as mães de meninos fizeram mais uso de "diretivos de atenção" (chamar a atenção da criança, pedindo que ela se aproxime ou olhe para algo), enquanto que os "diretivos de instrução" (verbalizar explicitamente o que deseja da criança) foram mais utilizados pelas mães de meninas.

Há variações também no manhês falado por mães com quadro de depressão em comparação às mães sem depressão. Ao longo do tempo, aquelas apresentam em toda sua extensão uma fala considerada menos emocional (e.g., por volta dos seis meses de vida do bebê há uma menor disposição em compartilhar sentimentos, contribuir para as trocas emocionais entre mãe e bebê e instruir ou confirmar a informação cognitiva a respeito das experiências perceptuais do bebê). Isto indica que elas são menos sensíveis a seus filhos, expressam menos afirmações e mais negações, fazem comentários mais críticos e mais hostis. Em seu discurso há menos características afetivas e informativas, mas ao longo do tempo, sua fala apresenta uma estabilidade, como se ignorasse o desenvolvimento do bebê (Herrera et al., 2004).

\section{Variabilidade}

Para podermos pensar a variabilidade no manhês, faz-se necessário compreender que esta fala resulta de um processo em que os parceiros estão em relação de interdependência. Todavia, a maioria dos estudos sobre tal fenômeno salienta, sobretudo, os comportamentos do adulto diante do bebê e não a relação entre ambos. Mas nossa visão a respeito das trocas adulto- -bebê é de que estas são co-reguladas, ou seja, acontecem numa dinâmica de co-construção. Isto significa compreender que, ao longo do tempo, os atos do bebê e dos seus parceiros vão se adaptando (e re-adaptando) um ao outro. Assim, as contribuições de ambos não podem ser analisadas separadamente, pois entre eles há uma influência mútua (Fogel, 1992, 1993; Fogel \& Thelen, 1987; Lyra, 1988).

\section{CO-CONSTRUÇÃO E TRANSFORMAÇÕES AO LONGO DO TEMPO}

A literatura sobre o manhês traz em sua grande maioria referências ao seu papel na aquisição de linguagem (Cavalcante, 2005; Cooper et al., 1997; Ferguson, 1964; Kuhl et al., 1997; Stern, 1977). É interessante observar que, para Tamis-LeMonda, Bornstein e Baumwell (2001), as conquistas quanto à linguagem não se devem apenas à criança ou à mãe, pois tanto a responsividade materna quanto o comportamento das crianças são responsáveis por tais aquisições. Liu et al. (2003) colocam que as medidas de fala da mãe não apresentam correlação entre habilidades cognitivas mais complexas (devido a seu nível educacional, renda, etc.) e clareza no discurso. Isto denota que o desenvolvimento léxico das crianças pode estar relacionado a uma combinação de fatores e não simplesmente às diferenças sociais - por exemplo, mães que usam vocabulário menos variado podem empregar mais meios de comunicação não verbal (Pan, Rowe, Singer \& Snow, 2005).

Para outros autores, entretanto, o foco principal desta fala não é auxiliar na aquisição de linguagem, mas sim o afeto (Matychuck, 2005). Segundo Nakata e Trehub (2004), bebês se mantêm mais atentos a estímulos auditivos mais emotivos, estereotipados, que se conservam estáveis ao longo das repetições. Logo, sua semelhança a uma melodia (Trainor et al., 2000) e seu tom mais dramático em função de agudeza e volume diferenciados (Stern, 1977) parecem enfatizar que a expressão emocional característica do manhês se torna primeiramente responsável por ajudar a criar e manter uma ligação entre cuidador e bebê (Trainor et al., 2000). É possível que este elo emocional facilite e/ou propicie a dinâmica de construção conjunta aqui proposta.

Cabe observar, portanto, que, seja com a função de auxiliar a aquisição de linguagem do bebê, ou de criar esta ligação afetiva com ele, algumas características do manhês evidenciam seu caráter co-construído. Neste sentido, o grande número de perguntas e imperati- 
vos e pausas mais longas entre os enunciados, que parecem servir para passar o turno ao bebê, trazem a impressão de que há um diálogo acontecendo, pois mesmo que o bebê não vocalize, a mãe age como se ele o fizesse (Cameron-Faulkner, Lieven \& Tomasello, 2003; Snow, 1977; Stern, 1977). Temos ainda que, segundo as descobertas de Snow, as mães incluem o bebê como parceiro com o qual dividem a autoria de seus enunciados, pois quase não fazem uso de monólogos, e mesmo rimas, ou músicas são recitadas como se fossem partes de uma peça aonde o bebê também tem um papel.

Além disto, temos que a alta freqüência de repetições ou reduplicações - mínimas variações em uma mesma palavra ou frase (Cavalcante, 2005; Cooper et al., 1997; Ferguson, 1964; Fogel, 1997) - pode evidenciar o propósito do adulto de dar ao bebê uma "segunda chance" para processar o que está sendo dito (Snow, 1977). O exagero prosódico e a simplicidade desta fala também podem indicar uma tentativa do adulto de habilitar o bebê a participar do processo de comunicação (Henning, Striano \& Lieven, 2005).

Assim, a extensão mais larga do som no manhês confere uma maior clareza à fala da mãe e auxilia os bebês a descobrirem as dicas acústicas apropriadas e a desenvolver redes neurais que codificam esta informação (Liu, Kuhl \& Tsao, 2003). Todavia, este espaçamento maior pode ser mais encontrado em palavras novas para o bebê, enquanto que aquelas que lhe são familiares e passíveis de serem deduzidas podem vir a ser subarticuladas (Kirchhoff e Schimmel, 2005). Portanto, o exagero presente no manhês parece enfatizar aspectos significativos da fala, fazendo com que seja mais fácil reconhecer seu significado (Fogel, 1997). Observamos, ainda, que esta questão salienta também o cunho histórico das trocas entre adulto e bebê. Trata-se da noção de que ao longo do tempo estas trocas construídas conjuntamente vão tecendo uma história. Assim, é possível que, em função da história que adulto e bebê constroem, as palavras destacadas numa frase sejam as mais significativas ou aquelas que eles sabem ser novas para o bebê.

Além deste aspecto co-construído do manhês, temos ainda que, ao longo do tempo, são evidenciadas mudanças nas mesmas, que indicam transformações nas relações adulto-bebê. Por exemplo, segundo Henning et al. (2005), no primeiro mês a fala da mãe reflete sua preocupação em estabelecer contato com o bebê. No terceiro mês, quando o comportamento dos bebês é mais comunicativo e as mães os reconhecem como parceiros mais ativos e mais comunicativos, elas podem elaborar sobre este contato, apresentando enunciados que crescem em quantidade, complexidade e diversidade. Snow (1977) observa que entre os três e dezoito meses, há um declínio nas referências à criança e um aumento nos enunciados que fazem alusão ao mundo. No início do primeiro ano de vida do bebê as mães falam sobre estados internos, sentimentos e experiências do bebê (e.g., se estavam cansados, com fome, etc.) e mais tarde falam sobre atividades, objetos e eventos relativos ao ambiente.

Tais transformações denotam uma percepção por parte do adulto de um interlocutor mais ou menos participativo (Henning et al., 2005). Sugerimos que este desenvolvimento nas trocas entre adultos e bebês ocorre por conta da corregulação estabelecida entre os parceiros, onde os atos do adulto e do bebê são construídos como parte de um processo de interação dinâmica, e o comportamento de um parceiro é continuamente ajustado em relação às respostas do outro (Fogel, 1992). Em nosso entender, temos o desenvolvimento destas trocas como resultado da construção conjunta entre os parceiros de modo que as transformações na fala materna indicam que a mãe se dirige a um parceiro que se mostra cada vez mais ativo, com novas habilidades, que passa a explorar o ambiente e que demonstra interesse por coisas outras além da esfera materna.

Segundo Henning et al. (2005), esta evolução no manhês também denota a tentativa de engajar os bebês no diálogo. Snow (1977) esclarece que as trocas mãebebê seguem um modelo conversacional, que se pauta pela reciprocidade na interação, i.e., a troca de informação entre parceiros acontece nas duas direções. Há, então, um ajuste ao interesse das crianças por diferentes objetos e atividades, à sua crescente necessidade de informações, à sua progressiva e diferente habilidade em participar e corresponder à interação e trocar turnos na conversa (Hening \& cols., 2005; Snow, 1977). Snow chama de orquestração este fenômeno que descreve a adaptação de um parceiro ao outro e que os coloca em condição de sintonia.

É interessante observar então que, dependendo da responsividade do bebê ao adulto (i.e., do quanto o bebê parece estar engajado na troca) e do propósito do comportamento (e.g. se a mãe deseja chamar a atenção do bebê, confortá-lo, etc.), são usados ritmos (Brazelton, Koslovsky \& Main, 1974, Stern et al., 1982), contornos de entonação (ascendente, decrescente, côncavo, sino e sino à direita) (Stern et al., 1982) e tipos de frases (solicitações ou diretivos) (Braz \& Salomão, 2002) diferenciadas. A repetitivi- 
dade pode também ser utilizada para conseguir a atenção dos bebês e enfatizar a mensagem que se quer passar ao bebê (Snow, 1977; Stern, 1977; Stern et al., 1982). Tais colocações são trazidas para o contexto deste trabalho, pois ainda que os autores acima citados não contemplem em suas colocações o caráter processual e relacional das trocas mãe-bebê, consideramos que suas descobertas podem ser utilizadas para mostrar aspectos relevantes na perspectiva aqui assumida. Podemos sugerir que as alterações no comportamento do adulto acima expostas estejam inseridas num contexto sistêmico, onde as mesmas são construídas conjuntamente pelos parceiros. Com isto compreendemos, por exemplo, que os tipos de frases, ritmos, entonação, entre outros aspectos escolhidos pelo adulto, resultam daquilo que foi/está sendo construído na relação estabelecida com o bebê.

Neste sentido, Rowe, Coker e Pan (2004) observaram que, em resposta ao comportamento paterno mais desafiador, as crianças falaram mais, usaram vocabulário mais diverso e produziram frases mais longas. Segundo Herrera, Reissland e Shepherd (2004), o fato da fala de mães com depressão se manter mais emocional ao longo do desenvolvimento do bebê pode demonstrar que estas estão menos dispostas a se ajustar às diferentes necessidades do bebê, pois parecem ignorar seu crescimento e sua necessidade de um discurso que ressalte informações. Porém, Murray (1998) enfoca também no papel do bebê e coloca que entre as díades compostas por mães com quadro de depressão é como se a interação ficasse fechada num ciclo de negatividade mutuamente responsiva (onde ambos os parceiros se fecham para o contato com o outro), o que pode culminar com o bebê se retirando antes de novas tentativas de um contato normal.

Este aspecto mútuo das trocas também foi verificado por Hsu \& Fogel (2003). Em seu estudo as vocalizações sem choro dos bebês eliciaram verbalizações maternas, nas quais as mães freqüentemente mudaram a forma de falar com o bebê, passando do manhês para imitação dos sons que o bebê produz. Os autores observaram então uma sincronização das respostas verbais e não verbais da mãe às vocalizações das crianças, onde o simples fato de ocorrer uma vocalização sem choro induziu a sincronização de respostas da mãe durante a interação face-a-face com o bebê.

Kajikawa, Amano e Kondo (2004) nos fornecem um exemplo que evidencia este crescente e mútuo ajuste entre os parceiros durante o processo de comunicação. Segundo os autores, diálogos na língua japonesa incluem com frequiência sobreposições ${ }^{3}$ de um parceiro sobre o outro, e a partícula ne é usada pelo falante para expressar empatia ou um pedido de aprovação. Nas díades estudadas por eles as mães começaram a usar mais sobreposições quando seus bebês começaram a produzir enunciados com duas palavras, e enunciados mais longos da criança tenderam a ser freqüentemente sobrepostos. Mas independentemente da duração, enunciados que continham $n e$ foram mais sobrepostos pelas mães do que aqueles sem ne. É como se a criança, ao usar esta partícula, convidasse a mãe a sobrepor seu enunciado.

O exemplo acima também indica que as variações na fala da mãe se referem à inserção (e consequente aprendizado) do bebê nas dinâmicas peculiares às trocas comunicativas que acontecem em seu grupo social. Como Gratier e Trevarthen (2007) colocam, a voz da mãe é a voz do seu contexto sócio-cultural, ela carrega a história de suas afiliações, de modo que, ao interagir com sua mãe (e também com outros parceiros), o bebê começa a se inserir na cultura. Ainda sobre este aspecto, segundo Kuhl (1998), a experiência lingüística resulta num tipo de aprendizado e os sistemas subjacentes à fala apresentam uma auto-organização acompanhada por uma perda de flexibilidade que variam conforme o input recebido. Isto quer dizer que, em função de estarem inseridos numa determinada cultura, os parceiros trilham um caminho por ela estabelecido, caminho este que fecha possibilidades para opções que estariam presentes em outras culturas.

Mas, se por um lado há perda de flexibilidade em função da adequação a padrões sócio-culturais, por outro pode-se evidenciar um aumento na flexibilidade quando se enfoca o desenvolvimento particular da comunicação de diferentes díades. Este aspecto se refere à noção de que, mesmo trilhando o caminho estabelecido pelo processo cultural, conforme apontado acima, há outro nível possível de criatividade, aquele que emerge da própria troca entre os sujeitos. Assim, a orquestração entre os parceiros propicia um afinamento entre eles, que lhes permite inovar nas trocas, construindo o novo. Trata-se do caráter criativo característico do processo de comunicação em que as próprias trocas comunicativas fazem emergir novos padrões de troca. Lyra, Pantoja, Cabral, Souza e Moutinho (1995) afirmam que mãe e bebê constroem a partilha através de uma forma dialógica específica, mas uma vez que a partilha se estabelece, esta díade pode ganhar em flexibilidade inovando quanto à forma através da qual o elemento previamente estabelecido será negociado. Além disto, segundo estas auto- 
ras, são as atividades partilhadas que constroem o novo e que fazem emergir significados para ambos os parceiros, e é através dessa construção partilhada de significados que os sujeitos dialógicos se constituem. Compreendemos que a idéia de co-construção do $m a$ nhês está inserida, particularmente nessa dinâmica dos dois sujeitos.

\section{Exemplo de Análise Microgenética da Comunicação Mãe-Bebê}

Os estudos realizados por Cavalcante $(1999,2005)$ tratam do papel do manhês no processo de emergência do sujeito e, apesar de terem como base referenciais teóricos diversos do nosso - e.g., a noção de que o sujeito de constitui na e pela linguagem (De Lemos, 1995) - encontramos aproximações interessantes e profícuas entre os mesmos. Identificamos nas colocações da autora afirmações que enfatizam as transformações nas relações entre adulto e bebê e também seu caráter de co-construção. Segundo ela, o manhês marca a constituição do sujeito, pois nesta fala diferenciada o bebê tem seu lugar de sujeito assegurado (Cavalvante, 2005). O que determina o lugar do bebê no discurso materno é o falsetto - a emissão de sons mais agudos - e o desaparecimento desta qualidade indica o surgimento do bebê enquanto sujeito falante. Além disto, desde o nascimento o bebê é tido como interlocutor pela mãe e as alterações prosódicas na fala materna indicam a percepção de um sujeito mais ou menos ativo vocalmente e dão lugar a outro sujeito, o bebê (Cavalcante, 1999).

Nossa proposta sugere que o manhês seja analisado sob um enfoque sistêmico e dinâmico, onde a comunicação é vista como um processo relacional, histórico, interdependente e criativo. Relacional e histórico porque o seu estudo tem como unidade de análise as transformações ocorridas ao longo do tempo nas relações entre os parceiros sendo, portanto, contrária a uma análise das contribuições de cada parceiro agrupadas a posteriori. Nossa perspectiva acerca do processo de comunicação propõe que cada troca comunicativa pertence a ambos os parceiros, impossibilitando a separação de um emissor, de um receptor e da própria mensagem e opõe-se, assim, a uma visão discreta da comunicação na qual se admite analiticamente a separação entre os parceiros e a mensagem comunicativa (Fogel, 1993). Trata-se, portanto, de investigar como a dinâmica das trocas interativas constrói novos padrões de organização da comunicação durante $o$ desenrolar do desenvolvimento.

É interessante observar que há um paralelismo entre nossa concepção a respeito da construção da co- municação adulto-bebê e o fenômeno da orquestração proposto por Snow (1977). Porém, este fenômeno, por si só, não explica como se desenrola o desenvolvimento desta comunicação. Para que tal tarefa seja alcançada propomos que o manhês seja investigado a partir de seu processo de mudança numa abordagem microanalítica. A seguir explicitaremos detalhes da análise da fala da mãe em nosso estudo.

\section{A Análise da Fala da Mãe e o Manhês}

Como participantes deste estudo, temos uma díade mãe-bebê, da qual dispomos de registros em vídeo das suas trocas no banco de dados do Laboratório de Comunicação e Linguagem na Primeira Infância (LabCom) - UFPE. Foram registradas semanalmente em vídeo as trocas entre mãe e bebê. Cada registro conta com aproximadamente 20 minutos de duração, sendo todos eles em situação de laboratório, isto é, numa sala, nas dependências do LabCom, onde há uma poltrona e diversos brinquedos. A díade foi filmada da $6^{\mathrm{a}}$ semana à $32^{\mathrm{a}}$ semana de vida do bebê. Na ocasião das filmagens as mães foram comunicadas de que se tratava de um estudo sobre o desenvolvimento do bebê, e foram orientadas a agir normalmente com eles, tal como fazem em suas casas. Analisamos a fala da mãe ao longo de todo o período estudado com o objetivo de compreender qual o seu papel no processo de diferenciação dos sujeitos. Visamos compreender, entre outros aspectos, como as mudanças na fala da mãe indicam o surgimento de transformações na relação entre mãe e bebê, ou seja, como as transformações nesta fala denotam a percepção por parte da mãe de um interlocutor mais ou menos ativo (Cavalcante, 1999; Henning et al., 2005).

Para isto, acompanhamos este desenvolvimento microgeneticamente, através de transcrições integrais dos vídeos, incluindo as falas da mãe e as ações, ou conjunto de ações de ambos os parceiros. Uma das etapas de nossa análise se refere à classificação destas falas quanto ao uso, ou não, do manhês.

Abaixo seguem exemplos das trocas entre mãe e bebê encontrados em três diferentes momentos do desenvolvimento do bebê. Trata-se de um bebê do sexo masculino, cujo nome foi alterado. Os enunciados em que a mãe se utiliza do manhês estão destacados com a letra " $\mathrm{M}$ " em parêntesis no início dos mesmos. Aqueles apresentados sem tal destaque referemse a falas não modificadas. 
Tabela 1

Uso do Manhês. Bebê com Oito Semanas de Vida

Exemplo 1: Idade do bebê: 8 semanas

( 1) Mãe - (Recosta-se e coloca o bebê deitado sobre ela)

( 2) Bebê - Com a cabeça abaixada, vocaliza alguns sons.

( 3) Mãe - Oi. Nenê. Psiu. O quê? Oxe. Oxente. Nenê. Ahn. (Respondendo às vocalizações do bebê).

( 4) (M) Vc gostou do chapéu? Gostou, não? Mamãe bota nela. Mamãe bota.

( 5) (M) Bota não, mamãe, esse chapéu é meu. Esse chapéu é meu. Chapéu é meu.

( 6) Bebê - Olha ao redor.

( 7) Mãe - (M) Ta olhando pra todo canto, né? (aproxima um brinquedo do bebê) (M) Dá um murro nele, dá. Dá um murro (4x). Dá um murro nele. Dá.

Exemplo 2: Idade do bebê: 8 semanas

( 8) Bebê - Olha ao redor e não olha para a mãe.

( 9) Mãe - (M) Que foi? Psiu. Marcos, Marcos, Marcos.

(10) Bebê - Esboça uma careta.

(11) Mãe - (M) Que foi? Que foi?

(12) Bebê - Inicia um chorinho.

(13) Mãe - (M) Não gostou, não?

(14) Bebê - Chora.

(15) Mãe - (M) Que foi? Que foi? Não chora, não, senão mamãe vai chorar também, viu? Chora, não, nenê que foi, hein?

(16) (M) Quer mamar, é? Quer?

(17) Bebê - Vocaliza.

(18) Mãe - É. Ah! Então tá certo.

(19) (M) Agora eu vou mamar. Não quero que me aperreie. Eu não quero. Eu não quero que me aperreie. Essa minha mãe fica me enrolando, essa minha mãe fica me enrolando.

(20) Bebê - Vocaliza.

(21) Mãe - (M) Mas eu vou dar seu mamazinho. Eu vou.

(22) Bebê - Continua vocalizando.

(23) Mãe - O quê? Ahn? Ahn? Peraí. (Respondendo às vocalizações do bebê)

Neste ponto do desenvolvimento do bebê vemos a mãe se utilizando primordialmente do manhês para se comunicar com o bebê. O manhês aqui é caracterizado por sons agudos, mas há também a presença de frases em tons mais graves, que são utilizados quando a mãe tenta confortar o bebê. Além disto, há momentos em que a mãe assume a posição do bebê e expressa o que ele possivelmente estaria dizendo. Em todas as vezes que a mãe fala pelo bebê ela se utiliza do manhês. Pode-se verificar ainda um dos aspectos relativos ao caráter dialógico ${ }^{4}$ das trocas, que se refere ao fato de muitas das falas da mãe serem respostas a ações do bebê.

Tabela 2

Uso do Manhês. Bebê com Vinte e Uma Semanas de Vida

\section{Exemplo 3: Idade do bebê: 21 semanas}

(24) Bebê - Vocaliza e mexe pernas e braços até que encosta os pés no brinquedo à sua frente.

(25) Mãe - (M) Tu vai dar pesada nela, é amor? Meu Deu do céu. Tu vai dar pesada na nenê. Ó ela chorando, ó.

(26) Bebê - Olha para o lado.

(27) Mãe - Psiu, ei, Marcos, ei. Você tá olhando pras coisas é, menino? Deixa de ser curioso. Ei, ó. Marcos, ó. (Pega uma almofada e pega a mão do bebê) Psiu. Psiu. Marquinhos. Psiu.

(28) Bebê - Continua olhando à sua volta. Não olha para a mãe.

(29) Olha para a mãe e depois desvia o olhar.

(30) Mãe - Marcos, ei, psiu.

(31) Bebê - Olha e mantém o olhar para a mãe. Sorri, movimenta braços e pernas.

(32) Mãe - Que foi, amor? Que foi?

(33) Bebê - Desvia o olhar

(34) Mãe - (M) Marquinhos, (esconde-se atrás da almofada e depois aparece) açou.

(35) Bebê - Olha para a mãe e depois desvia o olhar.

(36) Mãe - (M) Ei, marcos, olha pra mamãe, olha. Mamãe vai chorar (imita som de choro).

(37) Bebê - Olha para a ela e movimenta os braços.

(38) Mãe - (M) Marcos nem olha pra mãe dele. Eu vou cholá. 
Exemplo 4: Idade do bebê: 21 semanas

(39) Mãe - (Mostra um objeto ao bebê)

(40) Bebê - Olha ao redor. Não olha para o que a mãe está apontando.

(41) Mãe - (M) Marcos, deixa de olhar pra esse brinquedo. Oxe. Tô de mal de você. Ei, psiu.

Nesta sequência o bebê se mostra mais ativo e há uma diminuição no uso do manhês. Mas nos momentos em que se utiliza desta fala diferenciada, a mãe constrói enunciados que contêm itens lexicais infantilizados - neste caso, representados por palavras articuladas com modificações, presentes nas sequências 25,34 e $38-$, com muitas das sentenças centradas na experiência do bebê, entretanto, com uma inclusão maior de enunciados que fazem alusão ao mundo.

A partir disto, podemos sugerir que a fala da mãe exibe um paralelismo com o desenvolvimento do be- bê. Ou seja, as modificações na fala da mãe acima apontadas, incluída aqui a diminuição no uso do $\mathrm{ma}$ nhês, refletem sua percepção de estar diante de um interlocutor que, tanto demonstra interesses por objetos e ações que vão além dos limites de outrora, quanto paulatinamente vai se constituindo alguém a quem se dirige de uma maneira mais similar àquela utilizada entre adultos (AD). Tal paralelismo é evidenciado em todo o período por nós investigado, como poderá ser observado a seguir.

Tabela 3

Uso do Manhês. Bebê com Trinta e Duas Semanas de Vida

Exemplo 5: Idade do bebê: 32 semanas

(42) Mãe - (Com o bebê no colo) (M) Vou pegar.

(43) Bebê - Gargalha e coloca a mão na boca.

(44) Mãe - (M) Mamãe, vou pegar, mamãe, vou pegar. Vou pegar. Vou pegar. Tira a mão da boca, Marcos. Vou pegar você agora, você agora. Tira o dedo da boca, Marcos. Vou pegar.

(45) Bebê - Gargalha com a mão na boca.

(46) Mãe - (M) Vou pegar. Vou pegar.

Exemplo 6: Idade do bebê: 32 semanas

(47) Mãe - (Brinca com o puxador da cortina à sua frente e coloca a mão do bebê no puxador)

(48) Bebê - Brinca com o puxador da cortina.

(49) Mãe - (Balança o puxador da cortina)

(50) Bebê - Acompanha com o olhar.

(51) Mãe - Eta se escondeu, Marcos, se escondeu, cadê? Cadê?

(52) Bebê - Procura o puxador da cortina.

(53) Mãe - (M) Açou, pega.

(54) Bebê - Pega o puxador.

\section{Exemplo 7: Idade do bebê: 32 semanas}

(55) Bebê - Fica em pé e grita 'ah, ta ta ta'.

(56) Mãe - (Imita o som do bebê) 'ah, ta ta ta'.

(57) Mamãe

(58) Bebê - "Ruge".

(59) Mãe - (Grita acompanhando os sons do bebê) Aaaaaah.

(60) Bebê - Olha para a mãe

(61) "Ruge"

(62) Mae - (Grita novamente acompanhando os sons do bebê) Aaaaaah.

(63) Bebê - Olha para o outro lado.

(64) "Ruge".

(65) "Ruge" e dobra as pernas.

(66) Mãe - (M) Ô, nenê, quer subir na escada?

(67) (Cantarola)

(68) Bebê - Olha para ela e depois coloca a boca no pé.

(69) Mãe - (M) Oxente, quer comer o pé? Quer comer o pé? Marcos. Tá com fome? Você ta com fome? Você quer comer o pé?

(70) Mãe - (M) Então eu vou comer também. Eu vou comer esse pé (encosta a boca no pé do bebê).

(71) Bebê - Balança o pé, como se o oferecesse à mãe.

(72) Mãe - (M) Ah! Delícia.

(73) Bebê - Observa a mãe "comer o seu pé".

(74) Mãe - (M) Ô delícia.

(75) Bebê - Observa a mãe e ri. 
Esta sequência ilustra que a mãe diminui ainda mais a utilização do manhês, neste caso caracterizado por repetições (sequências 44 e 46), palavras modificadas (sequência 53), referências ao corpo do bebê (sequência 69-75), alguns dos enunciados apresentando sons mais agudos, todavia com uma diminuição na agudeza dos sons em relação aos primeiros meses. $\mathrm{O}$ conteúdo de sua fala revela uma diminuição no tom emocional da mesma, sendo que a mãe passa a se referir mais a situações do ambiente. Verificamos também que, conforme Hsu e Fogel (2003) apontam, quando o bebê faz vocalizações sem choro ela passa do manhês para a imitação das vocalizações do bebê, reforçando, assim, o caráter co-construído das falas. Podemos supor que tais mudanças se referem à percepção da mãe de um bebê mais ativo, i.e., ela começa enxergar seu parceiro com mais iniciativa nas trocas. Assim, ao mesmo tempo em que o bebê vai assumindo seu papel nestas trocas, também a mãe vai dandolhe lugar para ser um outro no diálogo, à medida que a mãe constrói com o bebê um lugar, uma posição, que vai se separando da sua própria neste contexto. Esses aspectos acima destacados dizem de um trabalho de construção, ainda sutil, da distinção entre o que é, mais puramente, uma interpretação da mãe acerca de movimentos e demonstrações espontâneas e genéricas do bebê, para características mais elaboradas daquilo que este bebê é e faz. Repetições (sequências 44 e 46), palavras modificadas (sequência 53) e referências ao corpo do bebê (sequências 44 e 68 a 75) parecem indicar uma maior flexibilidade da mãe como parceiro, decorrendo, justamente, da possibilidade de melhor separar e distinguir o que é típico daquele bebê particular, portanto, como parceiro naquele específico diálogo que está se construindo.

Em suma, observamos que durante todo o tempo analisado esta mãe se utiliza do manhês. Sua fala diferenciada é composta tanto por sons mais agudos quanto por sons mais graves. Os sons mais graves aparecem em enunciados em que a mãe deseja confortar o bebê. Mas verificamos também que ao longo do tempo estudado há uma mudança no uso do manhês. Inicialmente, a mãe se utiliza quase exclusivamente do manhês para se comunicar com o bebê. E nesta fala diferenciada seus enunciados são constituídos em grande parte por referências ao bebê, conforme Snow (1977) aponta. Em seguida, diante de um parceiro que começa a se mostrar mais ativo, há uma leve diminuição no uso do manhês, mas ao se utilizar desta fala seus enunciados ainda apresentam sentenças centradas na experiência do bebê, que passam a incluir enunciados que fazem alusão ao mundo externo aos parceiros, e.g. quando a mãe nota que o bebê está observando o local (sequência 27) ou quando se mostra chateada (sequência 41) por ele estar interessado no brinquedo e não nela. Na última sequência apresentada, o bebê está ainda mais ativo e apesar de a mãe continuar se utilizando do manhês para se comunicar com ele, encontramos também enunciados com entonação mais similar à fala dirigida a adultos, e ainda mais referências a situações do ambiente. Em nosso entender, estes dois aspectos acontecendo paralelamente - o aumento às referências ao ambiente associada à diminuição no uso do manhês, isto é, a diminuição no uso de uma fala com tom mais emocional, característica de uma fase mais inicial no desenvolvimento do bebê - indicam que a fala da mãe denota a percepção de um parceiro mais ativo, independente, e que progressivamente assume sua posição no diálogo.

Além disso, podemos observar a mãe acompanhando situações iniciadas pelo bebê (sequências 5562 e 68-75). Este aspecto vem reforçar nossa sugestão de que, ao mesmo tempo em que o bebê vai assumindo suas iniciativas nas trocas, a mãe também o vai percebendo como tal, lidando com ele em função desta percepção, e assim concedendo-lhe uma posição diferenciada da sua própria nas trocas.

Desde o início das trocas podemos verificar ainda a dinâmica de co-construção das mesmas, isto é, como ambos os parceiros contribuem conjuntamente para o funcionamento e desenvolvimento da comunicação, pois verificamos, conforme Snow (1977), Stern (1977) e Cameron-Faulkner et al. (2003) propõem, que muitas das verbalizações da mãe dão a impressão de que há um diálogo acontecendo, com enunciados aonde ela parece responder a ações e vocalizações do bebê. Neste mesmo sentido encontramos algumas ações do bebê que parecem atender a solicitações da mãe (sequências 47-54 e 69-75).

\section{CONSIDERAÇÕES FINAIS}

O levantamento bibliográfico de estudos a respeito da fala diferenciada dirigida a bebês, apresentado em nossa revisão da literatura, aliado às teorias norteadoras de nosso trabalho nos permite propor que o $\mathrm{ma}$ nhês apresenta um caráter de co-construção, conforme destacado no decorrer deste artigo. Propomos, ainda, que nossa análise microgenética nos permite identificar o processo de mudança pelo qual a fala da mãe -que incui o manhês -- passa durante a comunicação com o bebê e as transformações na relação entre ambos. Neste sentido, a diminuição no uso do manhês ao longo do tempo demonstra, sobretudo, as suas transformações inseridas na relação entre a mãe e seu bebê; desta forma, seu papel e importância no processo de 
constituição do sujeito é sugerido. Este papel se relaciona com a percepção, pela mãe, de um parceiro mais ativo, que é ancorado e fomentado nas relações e trocas com esta mãe. Isto é, ao mesmo tempo em que o bebê começa a se mostrar mais ativo, mais independente, a fala da mãe como um todo - e o manhês em particular - demonstra este fato nas características das trocas efetuadas entre a mãe e seu bebê. Assim, entendemos e propomos que a fala da mãe narra o processo de diferenciação dos sujeitos, ao mesmo tempo em que também constitui este processo de transformação.

\section{REFERÊNCIAS}

Bakhtin, M. (1999). Toward a philosophy of the act. Austin, TX: University of Texas Press.

Bakhtin, M. (2003). Estética da criação verbal (P. Bezerra, Trans.) São Paulo: Martins Fontes.

Bakhtin, M. (2007). Speech genres and other late essays. Austin, TX: University of Texas Press.

Bakhtin, M., \& Volochinov, V. N. (1992). Marxismo e filosofia da linguagem (M. Lahud \& Y. F. Vieira, Trans.). São Paulo: Hucitec.

Bertau, M. C., \& Gonçalves, M. (2007). Looking at "meaning as movement" in development: Introductory reflections on the developmental origins of the dialogical self. International Journal for Dialogical Science, 2, 1-13.

Braz, F. S., \& Salomão, N. M. R. (2002). A fala dirigida a meninos e meninas: Um estudo sobre o input materno e suas variações. Psicologia: Reflexão e Crítica, 15, 333-344.

Brazelton, T. B., Koslowski, B., \& Main, M. (1974). The origins of reciprocity: The early mother-infant interaction. In M. Lewis \& L. A. Rosenblum (Eds.), The origins of behavior - The effect of the infant on its caregiver (pp. 49-76). Princeton, NJ: John Wiley \& Sons.

Cameron-Faulkner, T., Lieven, E., \& Tomasello, M. (2003). A construction based analysis of child directed speech. Cognitive Science, 27, 843-873.

Cavalcante, M. (1999). Da voz à língua a prosódia materna e o deslocamento do sujeito na fala dirigida ao bebê (Tese de doutorado). Universidade Estadual de Campinas.

Cavalcante, M. C. B. (2005). Diálogos no berço: A interação mãebebê e a constituição do sujeito. Anais do I Congresso Internacional de Interação [CD-Rom]. São Leopoldo, RS.

Cooper, R. P., Abraham, J., Berman, S., \& Staska, M. (1997). The development of infants' preference for motherese. Infant Behavior an Development, 20, 477-488.

De Lemos, C. T. G. (1995). Língua e discurso na teorização sobre aquisição da linguagem. Letras de Hoje, 4, 9-28.

Englund, K. T., \& Behne, D. M. (2005). Infant directed speech in natural interaction: Norwegian vowel quantity and quality. Journal of Psycholinguistic Research, 34, 259-290.

Falk, D. (2004). Prelinguistic evolution in early hominins: Whence motherese? Behavioral and Brain Sciences, 27, 491541.

Ferguson, C. (1964). Baby talk in six languages. In J. J. Gumperz \& D. Hymes (Eds.) American Anthropologist, 66, 103-114.
Fogel, A. (1992). Movement and communication in human infancy: The social dynamics of development. Human Movement Science, 11, 387-423.

Fogel, A. (1993). The communication system: Co-regulation and framing. In A. Fogel (Ed.), Developing through relationships Origins of communication, self and culture (pp. 26-42). Chicago, IL: The University Chicago Press.

Fogel, A. (1997). Infancy: Infant, family and society. Saint Paul, MN: West Publishing Company.

Fogel, A., \& Thelen, E. (1987). Development of early expressive and communicative action: Reinterpreting the evidence from a dynamic systems perspective. Developmental Psychology, 23, 747-761.

Fogel, A., Garvey, A., Hsu, H-C., \& West-Stroming, D. (2006). Change process in relationships: A relational-historical research approach. Cambridge, MA: Cambridge University Press.

Garvey, A., \& Fogel, A. (2007). Dialogical change processes, emotions, and the early emergence of self. International Journal for Dialogical Science, 2, 51-76.

Granott, N., \& Parziale, J. (2002). Microdevelopment: A processoriented perspective for studying development and learning. In N. Granott \& J. Parziale (Eds.), Micro development: Transition processes in development and learning (pp. 1-28). Cambridge, MA: Cambridge University Press.

Gratier, M., \& Trevarthen, C. (2007). Voice, vitality and meaning: On the shaping of the infant's utterances in willing engagement with culture: Comment on Bertau's "On the notion of voice". International Journal for Dialogical Science, 2, 169-181.

Hauser, M. D. (1996). The evolution of communication. Cambridge, MA: MIT Press.

Henning, A., Striano, T., \& Lieven, E. V. M. (2005). Maternal speech to infants at 1 and 3 months of age. Infant Behavior \& Development, 28, 519-536.

Herrera, E., Reissland, N., \& Shepherd, J. (2004). Maternal touch and maternal child-directed speech: Effects of depressed mood in postnatal period. Journal of Affective Disorders, 81, 29-39.

Hsu, H-C., \& Fogel, A. (2003). Social regulatory effects of infant nondistress vocalization on maternal behavior. Developmental Psychology, 39, 976-991.

Kajikawa, S. Amano, S., \& Kondo, T. (2004). Speech overlap in japanese mother-child conversations. Journal of Child Language, 31, 215-230.

Kirchhoff, K., \& Schimmel, S. (2005). Statistical properties of infant-directed versus adult-directed speech: Insights from speech recognition. Journal of Acoustical Society of America, 117, 2238-2246.

Kuhl, P. K., Andruski, J. E., Chistovich, I. A., Chistovich, L. A., Kozhevnikova, E. V., Ryskina, V. L., Stolyarova, E. I., Sundberg, U., \& Lacerda, F. (1997). Cross-language analysis of phonetic units in language addressed to infants. Science, 277, 684-686.

Kuhl, P. K. (1998). Language, culture and intersubjective: The creation of shared perception. In S. Bråten (Ed.), Intersubjective communication and emotion in early ontogeny (pp. 297315). Cambridge, MA: Cambridge University Press.

Lee, K., \& Karmiloff-Smith, A. (2002). Macro- and micro developmental research: Assumptions, research strategies, constraints, and utilities. In N. Granott \& J. Parziale (Eds.), Micro 
development transition processes in development and learning (pp. 243-265). Cambridge, MA: Cambridge University Press.

Liu, H.-M., Kuhl, P. K., \& Tsao, F.-M. (2003). An association between mothers' speech clarity and infants' speech discrimination skills. Developmental Science, 6, 1-10.

Lyra, M. C. D. P. (1988). Transformação e construção na interação social: A díade mãe-bebê (Tese de doutorado). Universidade de São Paulo.

Lyra, M. C. D. P. (2000). Desenvolvimento de um sistema de relações historicamente construído: Contribuições da comunicação no início da vida. Psicologia: Reflexão e Crítica, 13, 257-268.

Lyra, M. C. D. P (2006). Desenvolvimento como processo de mudança. In L. L. Meira \& A. G. Spinillo (Eds.), Psicologia cognitiva: Cultura, desenvolvimento e aprendizagem (pp. 170189). Recife: Editora Universitária da UFPE.

Lyra, M. C. D. P. (2007). Modeling the dynamics of meaning construction: Appropriation of the home environment. Culture \& Psychology, 13, 179-188.

Lyra, M. C. D. P., \& Bertau, M. C. (2008). Dialogical practices as basis for self. Studia Psychologica, 8, 175-196.

Lyra, M. C. D. P., Pantoja, A. P. F., Cabral, E. A., Souza, M., \& Moutinho, A. K. (1995). A produção vocal do bebê: Construção partilhada pela díade. Psicologia: Teoria e Pesquisa, 11, 1-6.

Marková, I. (1990). A three-step process as a unit of analysis in dialogue. In I. Marková \& K. Foppa (Eds.), The dynamics of dialogue (pp. 129-146). New York, NY: Springer-Verlag.

Marková, I. (2006). Dialogicidade e representações sociais: As dinâmicas da mente. Petrópolis: Vozes.

Matychuck, P. (2005). The role of child-directed speech in language acquisition: A case study. Language Sciences, 27, 301379.

Messer, D. J. (1994). The development of communication: From social integration to language. Chichester, England: Wiley.

Murray, L. (1998). Contributions of experimental and clinical perturbations of mother-infant communication to the understanding of infant intersubjective. In S. Bråten (Ed.), Intersubjective communication and emotion in early ontogeny (pp. 127143). Cambridge, MA: Cambridge University Press.

Nakata, T., \& Trehub, S. E. (2004). Infant's responsiveness to maternal speech and singing. Infant Behavior \& Development, 27, 455-464.

Pan, B. A., Rowe, M. L., Singer, J. D., \& Snow, C. E. (2005). Maternal correlates of growth in toddler vocabulary production in low-income families. Child Development, 76, 763.
Redford, M. A., Davis, B. L., \& Miikkulainen, R. (2004). Phonetic variability and prosodic structure in mothers. Infant Behavior and Development, 27, 477-498.

Rowe, M. L., Coker, D., \& Pan, B. A. (2004). A comparison of fathers' and mothers'talk to toddlers in low-income families. Social Development, 13, 278-291.

Schieffelin, B. B. (1979). Getting it together: An etnographic approach to the study of the development of communicative competence. In E. Ochs \& B. B. Schieffelin (Eds.), Developmental pragmatics (pp. 73-108). London: Academic Press.

Sheridan, S. R. (2005). A theory of marks and mind: The effect of notational systems on hominid brain evolution and child development with an emphasis on exchanges between mothers and children. Medical Hypotheses, 64, 417-427.

Snow, C. E. (1977). The development of conversation between mothers and babies. Journal of Child Language, 4, 1-22.

Stern, D. (1977). The first relationship: Mother and infant. Cambridge, MA: Harvard University Press.

Stern, D. N., Spieker, S., \& MacKain, K. (1982). Intonation contours as signals in maternal speech to prelinguistic infants. Developmantal Psychology, 18, 727-735.

Tamis-LeMonda, C. S., Bornstein, M. H., \& Baumwell L. (2001). Maternal responsiveness and children's achievement of language milestones (maternal role in language acquisition). Child Development, 72, 748-767.

Thelen, S., \& Corbetta, D. (2002). Microdevelopment and dynamic systems: Applications to infant motor development. In $\mathrm{N}$. Granott \& J. Parziale (Eds.), Micro development: Transition processes in development and learning (pp. 59-79). Cambridge, MA: Cambridge University Press.

Trainor, L. J., Austin, C. M., \& Desjardins, R. N. (2000). Is infantdirected speech prosody a result of the vocal expression of emotion? Psychological Science, 11, 188-195.

Valsiner, J. (1997). Culture and the development of children's action. New York, NY: John Wiley \& Sons.

Van Geert, P. (2003) Dynamic systems approaches and modeling of developmental processes. In J. Valsiner \& K. Conolly (Eds.), Handbook of developmental psychology (pp. 640-672). London: Sage.

\section{Notas:}

1 Tradução de "prosody".

2 Tradução de "higher pitch".

3 Tradução de "overlaps" - um parceiro começa a falar enquanto o outro ainda está falando.

4 Referimo-nos ao dialogismo, proposição teórica que estabelece uma perspectiva relacional quanto aos indivíduos (Bertau \& Gonçalves, 2007; Marková, 1990), que encontra grandes contribuições nas obras de Bakhtin (1999, 2003, 2007). Em conformidade com autores como Lyra (2006; 2007), Lyra e Bertau (2008), Garvey e Fogel (2007), Fogel, Garvey, Hsu e West-Stroming (2006), ainda que o status do diálogo seja principalmente relacionado ao uso da linguagem, temos que a idéia de que a dialogicidade - noção de que qualquer expressão humana existe sempre em relação a outras expressões, onde enunciados falados, textos escritos, pensamentos e ações sempre representam uma resposta a enunciados, textos, ideias e ações previamente colocados - está presente desde o início da vida (Bertau \& Gonçalves, 2007). 